\title{
Albert Gielen \\ De originaliteit van het plagiaat. Gimmick! eigent zich op postmoderne wijze postmoderne beeldende kunst toe
}

\begin{abstract}
Gimmick! written by Joost Zwagerman is a postmodern artist's novel. The protagonist Walter van Raamsdonk, in short called Raam, is a visual artist, just like his friends Groen and Eckhardt. This article analyzes the novel as a postmodern phenomenon centered on postmodern visual art. Because the novel and the visual arts in the novel can be characterized as postmodern, it is investigated which characteristics of the postmodern can be found in both disciplines. To what extent does the novel reflect postmodern art? Citing in both disciplines has far-reaching consequences for the appearance of visual art and for the novel.

Keywords: Joost Zwagerman, artist's novel, visual art, postmodernism, Rob Scholte
\end{abstract}

\section{$1 \quad$ Inleiding}

Gimmick! ${ }^{1}$ van Joost Zwagerman (1963-2015) genereerde veel publiciteit en niet op de laatste plaats omdat deze kunstenaarsroman als een sleutelroman werd opgevat. Volgens Peter V. Zima is de schilder Eckhardt uit de roman op de beeldende kunstenaar Rob Scholte (1958) gebaseerd. ${ }^{2}$ Scholte zelf zou zich daarentegen in het personage Groen herkend hebben, aldus Ruud A.J. Kraaijeveld in Ons Erfdeel: "Het reportage-achtige karakter van het boek heeft ook voor enige opwinding in het Amsterdamse kunstenaarswereldje gezorgd. De schilder Rob Scholte zou Zwa- 
german ernstig bedreigd hebben om het negatieve beeld dat de schrijver van hem geeft (in de figuur Groen; de Volkskrant, mei 1989)". 3 Hier gaat het niet zozeer om de gelijkenis van de personages met reëel bestaande beeldende kunstenaars, maar om de kunst die een procedé hanteert dat als typisch postmodern is op te vatten. De vraag kan gesteld worden in hoeverre de roman Gimmick! zich de postmoderne beeldende kunst toeeigent.

Op zich is de ergernis van Rob Scholte opmerkelijk, omdat Zwagerman een productieprocedé toepast dat ook Scholte hanteert. In het navolgende analyseer ik de roman Gimmick! op postmoderne eigenschappen en analyseer ik vervolgens de beeldende kunst die Zwagerman in zijn roman betrekt, want feit is wel dat Zwagerman de kunst van toen jonge kunstenaars in zijn roman presenteert. De roman en de beeldende kunst in de roman zijn tijdgenoten van elkaar. Het is niet zo dat er in een roman uit 2020 een beeldhouwer uit de middeleeuwen aan het woord is. Omdat het om tijdgenoten gaat, gaat het ook om vergelijkbare eigenschappen van de roman en de beeldende kunst. Beeldende kunst vormt in de roman de verbindende schakel tussen de personages en de gebeurtenissen. Per discipline heeft het begrip postmodernisme andere betekenissen. De vraag is of dat in het geval van Gimmick! ten opzichte van de groep Scholte eveneens van toepassing is en hoe een postmoderne kunstenaarsroman op postmoderne wijze postmoderne kunst opneemt.

Protagonist in Gimmick! (1989) is de dan 22-jarige ik-verteller Walter van Raamsdonk (1963), kortweg Raam genoemd. Hij is kunstschilder. De roman speelt dan ook in het Amsterdamse kunstenaarsmilieu dat gegroepeerd is rond discotheek Gimmick. Raam was aanvankelijk succesvol, maar daaraan is een einde gekomen sinds hij lijdt onder een creatieve blokkade. Zijn vrienden, Groen en Eckhardt, hebben daarentegen in toenemende mate succes. De reden van Raams blokkade heeft te maken met zijn verbroken relatie met Suzan Fortuyn, door Raam Sam of Sammie genoemd. De roman is daarom dan ook nog een liefdesroman te noemen.

$\mathrm{Na}$ de proloog, volgen drie periodes die opeenvolgend voornamelijk in Amsterdam, in Florence en op Tenerife, en tot slot in New York en Amsterdam spelen. De proloog past bij het derde deel in New York. De delen dragen als titel de namen van de maanden: 'Deel 1: oktober', 'Deel 2: januari' en 'Deel 3: april'. Het leven van de drie vrienden bestaat voornamelijk uit discobezoek en seksuele uitspattingen. Groen en Eckhardt proberen met hun werk zoveel mogelijk geld te verdienen en dat lukt goed, maar niet zozeer door hun artistieke inspanningen in het atelier, 
maar vooral door zoveel mogelijk media-aandacht te genereren en te netwerken. Daarnaast zijn zij eveneens in de liefde dan wel in het bevredigen van lust succesvol. Raam behoort ook tot dat kunstwereldje, maar is toch een buitenstaander, vooral door zijn artistieke blokkade en door zijn verdriet om Suzan die hem in de steek heeft gelaten.

In het eerste deel, in het hoofdstuk 'Namen en slogans', bezoekt Raam de psychisch labiele collega-kunstenaar Alex Menkveld die in een psychiatrische inrichting verblijft. Alex had eerder tentoonstellingen in Amsterdam, Den Haag, Lyon en Düsseldorf en verdiende uitstekend, maar minder dan de vader van Raam en nog veel minder dan Eckhardt. Alex geeft echter niets om geld en schenkt Raam dan ook drie abstracte schilderijen. In het derde deel is Raam terug in Amsterdam en wordt zijn periode in New York, waar hij samen met Groen en Eckhardt geweest is, in flashbacks ter sprake gebracht. In het laatste deel voltrekken zich drie voor Raam belangrijke gebeurtenissen. Op de eerste plaats is daar de beoordeling van een commissie die over de toekenning van een subsidie gaat. Hij moet dan wel kunnen aantonen dat hij in de toekomst met belangwekkend werk zal komen. Dat kan hij niet, totdat hij op het idee komt om de abstracte schilderijen van Alex Menkveld als de zijne te presenteren en dat als een nieuwe ingeslagen weg te verkopen. De commissie trapt erin. Op de tweede plaats gaat het om de groepstentoonstelling The Amsterdam Dream waaraan hij met Groen en Eckhardt meedoet. Daar stelt Raam oud werk tentoon. De openingsavond eindigt in een drugsroes en een vechtpartij. Dit leidt tot de derde belangrijke gebeurtenis en dat betreft Sam. Als hij dronken en onder invloed van drugs is, meent hij met Sam te doen te hebben die hem mee naar huis neemt, maar het blijkt het meisje met de zonnebril uit deel één te zijn. Ook nu leidt het tot niets.

Peter V. Zima ziet Gimmick! in Der europäische Künstlerroman. Von der romantischen Utopie zur postmodernen Parodie (2008) als behorend tot het genre kunstenaarsroman. De vraag wat een kunstenaarsroman tot een kunstenaarsroman maakt, is op velerlei manieren te beantwoorden. Dat de protagonist een kunstenaar (componist, beeldende kunstenaar, schrijver en zo verder) moet zijn is logisch, maar niet toereikend. Bovendien betreft het in de romantiek een ander type kunstenaarsroman dan in postmoderne tijden. Om te kunnen zien hoe afwijkend de postmoderne kunstenaarsroman is van bijvoorbeeld de moderne of laatmoderne kunstenaarsroman, eerst aandacht voor wat Roberta Seret in Voyage Into Creativity. The Modern Künstlerroman (1992) beschrijft. 
In de moderne kunstenaarsroman is volgens Seret de weg of de reis naar, en de ontwikkeling van, het kunstenaarschap van belang. Het motief van de reis van de kunstzinnige protagonist is dan ook voor haar het bepalende structuurelement. Het doel van de roman en de kunst is: de protagonist vindt in kunst zijn homeland. Om dat zo belangrijke homeland te bereiken is de meest voor de hand liggende reis de metaphorical voyage, in metaforisch opzicht kan er sprake zijn van een "psychological voyage, social voyage, and artistic voyage"

- The psychological voyage: het kan hierbij gaan om de reconstructie van de jeugd van de protagonist: "His [the young boy's] experiences in school, at home, or with friends tend to reinforce his need to withdraw from abrasive influences indicating future patterns of isolation and escapism which will later be sublimed in art". 5 Hiertoe behoort ook de archetypische trek van de protagonist van het dorp naar de stad.

- The social voyage: de kunstenaar is op zoek naar zijn identiteit: "At the moment when he frees himself psychologically from parental and external pressures, he consciously decides which position he [as an artist] will take vis-à-vis society, either one of participation or one of observation". 6

- The artistic voyage: dit is een typisch motief in de Künstlerroman, de reis door de kunst: "He [the artist] gropes for inspiration, calls forth muses, and struggles with fate, having no peace until he achieves self-realization and creates art". ${ }^{7}$

Aan de artistieke reis valt het meeste gewicht toe te kennen, omdat de ontwikkelingen van de kunstenaar-protagonist, volgens Seret, gelijk opgaan met die van de kunstenaar-auteur in de zoektocht naar overeenkomstige idealen. De laatste moet in zijn eigen geest en jeugd te rade gaan en zijn ervaringen en de situaties herbeleven om ze te vereeuwigen. De kunstenaar-protagonist representeert een reflectie op hoe de samenleving de kunstenaar waarneemt en hoe het zelfbeeld van de kunstenaar de poëtische afstand tussen auteur en protagonist beïnvloedt. De auteur en de protagonist kunnen overeenkomstige redenen hebben om door de kunst te reizen: "The creator voyages through art for similar reasons; in doing so the author writes a Künstlerroman". ${ }^{8}$ In wezen is dit "the voyage into creativity" (idem), ofwel naar "the creator's homeland". ${ }^{9}$ De kunst moet het thuis van de kunstenaar geworden zijn en dat is in de postmoderne kunstenaarsroman problematisch. 


\section{Gimmick! als postmoderne roman}

Gimmick! is een representant van de postmoderne kunstenaarsroman waaraan de genoemde Zima in Der europäische Künstlerroman een paragraaf wijdt: "Allerdings gehört Gimmick! - wie Süskinds Das Parfum eindeutig der 'lesbaren' Postmoderne an". ${ }^{10}$ Het parodistische karakter van de postmoderne kunstenaarsroman acht hij van groot belang, omdat dit het einde betekent van kunst als drager van een maatschappelijke utopie en het belang van kunst door secularisering, sociale differentiatie en het marktdenken afneemt. ${ }^{11}$ Er komt een einde aan de positie van de kunstenaar als genie, ziener en criticus en daarvoor in de plaats komt een functie als 'kunstproducent'. De roman wordt geschreven met het oog op een verfilming en dit dwingt de auteur zich commercieel op te stellen en bereid te zijn om concessies met de cultuurindustrie te sluiten. ${ }^{12}$ De kunstenaar wordt een buitenstaander en is zelfs bijna niet meer als kunstenaar te herkennen. ${ }^{13}$ Niet meer als ziener, maar als aap. De postmoderne schrijver herschept niet alleen door na te apen of een spel te spelen en dat verklaart Zima als volgt:

Sie [de postmoderne schrijvers] setzen die moderne Kritik an Religionen, Ideologien, Pseudowissenschaften und mondänen Maskeraden fort, indem sie auf ideologiekritischer Ebene noch einen Schritt weiter gehen, um auch den Kunstbegriff zu reflektieren und kritisch zu erlegen [cursief van Zima]. ${ }^{14}$

Door met oude vormen te spelen of door met intertekstualiteit de betekenis van oude teksten te veranderen, wordt wat kunst of literatuur is in twijfel getrokken. In tegenstelling tot moderne literatuur ziet de postmoderne literatuur af van esthetische en politieke utopieën. ${ }^{15}$ De romancier ziet de kunstenaar niet meer als schepper van niet na te maken originelen, waardoor hij zijn geloofwaardigheid verliest. Het gevolg is dat de kunstenaarsroman alleen nog geparodieerd kan worden: „Gimmick! ist insofern eine Parodie des Bildungs- und Künstlerromans, als der heranwachsende Held die Nichtigkeit ästhetischer Begriffe und Werte erfährt, statt wie [James] Joyces Stephen, [Marcel] Prousts Marcel oder [Thomas] Manns Adrian Leverkühn den Weg zur Kunst zu finden und ihn als den einzig wahren zu erkennen". 16

Hoe wordt dit in de roman tot uitvoering gebracht? Eerst de titel. Kunst is een gimmick, waarbij het niet meer om de kunst, maar om de marktwaarde gaat. The Concise Oxford Dictionary legt de nadruk op het econo- 
mische aspect van een 'gimmick': "a trick or device, esp. to attract attention, publicity, or trade". ${ }^{17}$ In Gimmick legt Eckhardt het aan Raam uit: "Kunst is een kwestie van timing, marketing en conceptual strategy, ik noem maar wat". ${ }^{18}$ Het hoeft in elk geval niet origineel te zijn. Dat blijkt wanneer Raam Groen in zijn studio bezoekt waar deze bezig is de tekst in Japanse oorlogsdocumenten te veranderen. De herkomst van de documenten is onbekend en dan blijkt dat een Japanse vriend van Groen ze gemaakt heeft. Raam vraagt: "'Dus het is geen origineel document?'. Groen reageert geërgerd: 'Origineel, origineel, wát nou origineel?'. Dolfijntje, de vriendin van Groen zegt: 'Origineel. O-rie-sjie-neel, [...]. Als je het een paar keer achter elkaar zegt, begint het heel maf te klinken. Net een ziekte'. Groen stemt daarmee in: 'Originaliteit is een ziekte. Wij [Groen en Dolfijntje] houden van alles wat voos en onecht is"." ${ }^{19}$

Het opmerken van originaliteit betreft ook mensen. Als Raam in het derde deel Sam per ongeluk ontmoet bij Felix Danije, eveneens beeldende kunstenaar maar een die meer met zijn drugshandel verdient, maken ze een afspraak. In een café waar hij met haar zit, denkt hij "En ze kijkt me aan met - met die allejezusgrote ogen, die natuurlijk niet van haarzelf zijn maar die ze uit een portret van Isabelle Adjani of van Marouschka Detmers heeft geknipt en die ze vervolgens over haar eigen ogen heeft geschoven". ${ }^{20}$ Veel mensen die Raam ontmoet vertonen gelijkenis met beroemde personen, zoals de stripster die er als Whitney Houston uitziet ${ }^{21}$ of het meisje achter de bar in Gimmick als Marilyn Monroe. ${ }^{22}$

Eckhardt oppert wel het postmoderne programma: "wij zien in dat de toekomst een toekomst is van annexeren, kopiëren, plagiëren desnoods". 23 Het is dan ook veelzeggend dat wanneer Raam eindelijk zijn atelier weer eens betreedt, hij het interieur beschrijft maar niets over verf of kwasten en dergelijke zegt. Wel vermeldt hij een "fotokopieermachine die vier dagen na aanschaf al kapot was". ${ }^{24}$

In de roman zijn verschillende plaatsen aan te wijzen waarop Zima's opmerking - "In dem von Zwagerman dargestellten Künstlermilieu geht es nicht mehr um Verfahren, Stile oder Themen, sondern um Marktstrategien und Markterfolge" - van toepassing is. ${ }^{25}$ Zo zegt Eckhardt: "Er zijn geen goeie of slechte kunstenaars meer, Walter, er zijn kunstenaars mét geld en er zijn kunstenaars zónder geld en de kunstenaars zonder geld zijn eigenlijk helemaal geen kunstenaars". ${ }^{26}$ Eckhardt beschrijft zijn artistieke activiteiten: "Ik heb nu vier mensen in dienst die het werk doen. Zij schilderen, ik lever de concepten, lever het materiaal. Ik denk aan mezelf. [...] ik geef interviews, concentreer me op internationale contacten". ${ }^{27}$ Groen 
blijkt de expressie middels kunst niet het belangrijkste te vinden: "Pas als de schijnwerpers op je zijn gericht heb je kwaliteit [...]. Ik ben op de televisie dus ik besta". ${ }^{28}$ Groen is dan ook degene die veel aandacht besteedt aan relaties, het netwerk, de strategie, de contacten: "Contacten met galeriehouders, met collega's". ${ }^{29}$

In het derde deel volgt de apotheose - de opening in het Stedelijk Museum in Amsterdam van de groepstentoonstelling 'The Amsterdam Dream' waaraan ook Raam, Eckhardt en Groen meedoen. Raam ziet tijdens het openingswoord van de minister het volgende:

Achter in de zaal praten beleggers over de laatste ontwikkelingen op het gebied van de allermodernste kunst en even verderop hebben de kunstenaars het over hun laatstverdiende ton. De schilders zijn gekleed alsof ze net van de optiebeurs komen en de beursspeculanten dragen artistiekerige dasspeldjes en Keith Haring-sokken onder hun glimmende Dr. Adamsschoenen. Kunstenaars en moneymakers, moneymakers en kunstenaars, de ene groep wil dolgraag op de andere lijken en daardoor is er zowat niks meer dat hen van elkaar onderscheidt. Tijd is geld; creativiteit is méér geld. Zoiets. ${ }^{30}$

De museumdirecteur van het Stedelijk Museum zegt tijdens zijn openingswoord over de titel van de tentoonstelling dat deze ironisch is, waaruit blijk hoe ongrijpbaar en vol elan deze generatie zich profileert: "Ironie, cynisme, de vloek van het postmoderne denken, de versnippering van verworvenheden - The Amsterdam Dream geeft inzicht in hoe jonge beeldende kunstenaars worstelen met en antwoord geven op de vraagstukken en problemen van deze tijd". 31

De tentoonstelling 'The Amsterdam Dream' wordt als volgt beschreven: "In de hoofdzaal natuurlijk het werk van Eckhardt. In het midden van de zaal zijn nieuwste werkstuk: tientallen op elkaar gestapelde pakken Dash-waspoeder. Eromheen een uit glas opgetrokken piramide. Verder hangen er nog een paar van Eckhardts op Tenerife gemaakte schilderijen: zorgvuldig overgeschilderde vignetten van Mercedes Benz, His Masters Voice, McDonald's". ${ }^{32}$

Zima's opmerking over marktstrategieën en succes op de kunstmarkt is van toepassing op Groen en Eckhardt, maar Raam houdt zich daar verre van. Raam laat zich niet over kunst uit, behalve hier:

Ik ben geboren in '63, dus waarom maak ik niet een mooi postmodern portret van John F. Kennedy? Waarom schilder ik niet een paar platen- 
hoezen of boekomslagen na? Of iets met tandpasta: Elmex, Zendium, Prodent, Aqua Fresh. Of een waanzinnig plat schilderij met daarop de flacons van Head \& Shoulders, Palmolive, Badedas, Andrélon. [...] Kortom, het gaat in de kunst om namen en om slogans $[\ldots]]^{33}$

Ook hier spreekt weinig originaliteit uit, omdat de objectkeuze aan die van Andy Warhol (1928-1987) doet denken.

Ook wanneer anderen Raam inhoudelijk over kunst aanspreken, ontwijkt hij de vraag of weigert te reageren. Dat laatste is het geval als Eckhardt Raam van de noodzaak om nieuw werk te maken probeert te overtuigen - Raam reageert niet. Eckhardts aanmoediging om een nieuwe 'beeldcode' te ontwikkelen lijkt hem te ontgaan. Tijdens hun bezoek aan New York vertelt Groen in een bar een expositie te hebben geregeld. Daar gaat Raam niet op in door te zeggen "hoe lekker je in New York Japans kunt eten". ${ }^{34}$

Tijdens het diner na de opening wordt hij aangesproken door "een goedgeklede vijftiger met een buitensporig gebruinde harses en volumineuze wallen onder z'n ogen". De man zegt dat hij Raams bijdrage aan de tentoonstelling sterk vindt, alleen jammer dat het oud werk is. Raam gaat er niet op in en zegt dat zijn vriendinnetje gebeld heeft. De man gaat verder en vergelijkt Raams werk met dat van Eckhardt en Groen en ziet veel overeenkomsten. Op de vraag wie hem (Raam) beïnvloedt, begint Raam weer over zijn (ex-)vriendinnetje. Tot slot zegt de man dat hij Raam later nog eens zou willen spreken. Raam vraagt: "Waarover dan?". 35

De climax volgt als Raam in zijn atelier bezoek krijgt van een vrouw van de Raad voor de Kunst en een ambtenaar die een advies moeten uitbrengen aan de afdeling Rijkssponsoring Beeldende Kunst. Hij moet concrete toekomstplannen presenteren om in aanmerking te komen voor een subsidie van 40.000 gulden, maar hij heeft geen enkel plan. Dan schieten hem de drie schilderijen van Alex Menkveld te binnen en vervolgens toont hij die schilderijen aan zijn beoordelaars: "Ik ben bezig aan nieuw werk, maar ja, dat is zo... zo anders dan wat ik tot nu toe heb gemaakt". De vrouw is enthousiast en zegt: "dit is wérkelijk een ommezwaai. Wie had kunnen denken dat jij ooit nog eens abstract zou gaan werken?". ${ }^{36}$ De vrouw zegt dat ze een positief advies zal uitbrengen. Als de ambtenaar en de vrouw weg zijn wordt deze scène afgesloten met: "Veertigduizend. Het geluid van de deur van mijn atelier die achter me dichtslaat klinkt me goed in de oren. Hier zien ze mij de eerste tijd niet 
meer" ${ }^{37}$ Inderdaad zal hij niet meer in zijn atelier terugkeren en het geld allerminst aan schildermateriaal besteden.

\section{Citeren}

Een eenduidige definitie van postmodernisme bestaat niet, maar er is wel een aantal constanten aan te wijzen die bij verschillende literatuurwetenschappers genoemd worden. Marcel Janssens geeft een korte karakteristiek: "the fragmentation of great ideological frameworks would be the key element of postmodern writing"38, maar daarbij merkt hij ook het volgende op: "Another important characteristic of postmodern writing is the ironic inclusion of pulp texts in so-called 'serious' literature". ${ }^{39}$ Seijdel stelt dat de term 'postmodernisme' staat voor het wegvallen van de "grote (ideologische) Waarheden" en van de "hoofdcodes van het maatschappelijk leven", en voor het einde van "het project van het modernisme". Het gevolg is dat het "moeilijk is om nog te geloven in de authenticiteit, originaliteit en uniciteit van kunst, nu het duidelijk is dat ook de kunst volledig is opgegaan in het ruilwaardesysteem van het kapitalisme, en evengoed een consumptieartikel is waarvan het aura louter op fetisjisme en marktwaarde berust". ${ }^{40}$ Het is duidelijk dat fragmentatie, ironie, de vermenging van high en low brow, twijfel aan authenticiteit, originaliteit en uniciteit van de artistieke uiting kernbegrippen zijn.

Paul Römer gaat op zoek naar verwijzingen en citaten in Gimmick!, met als argument dat de wijze waarop de intertekstualiteit die in Gimmick! wordt toegepast "een fundamenteel aspect van het postmodernisme in de literatuur" is. ${ }^{41} \mathrm{Er}$ is een verwijzing naar de film Manhattan (1979) van Woody Allen (1935) als Raam zich herinnert dat Sam en hij na een liefdesnacht en -dag in bed eten: "s Avonds lieten we Chinees eten bezorgen. Ik morste bijna het halve bord nasi in bed". ${ }^{42}$ Volgens Römer is in grote lijnen dezelfde scène in Manhattan te zien. ${ }^{43}$ Maar het zijn vooral de postmoderne literaire werken van auteurs als Bret Easton Ellis (1964), Jay McInerney (1955) en Tama Janowitz (1957), gezamenlijk het groepje 'Brat Pack-novelists' genoemd, die Gimmick! beïnvloedt hebben. De personages die in hun romans voorkomen typeert Römer als "in grote steden als New York en Los Angeles levende personages, die zich nergens meer om lijken te bekommeren. Emoties worden door het gebruik van drugs (met name cocaïne) in de kiem gesmoord, medeleven is hen onbekend. Hun gedachtenwereld wordt gekenmerkt door oppervlak- 
kigheid en afstandelijkheid; zij leiden een pretentieloos leven". ${ }^{44}$ De overeenkomst tussen Gimmick! en The Rules Of Attraction (1987) van Bret Easton Ellis is zo groot dat Römer schrijft: "het lijkt alsof Zwagerman deze letterlijk heeft vertaald". ${ }^{45}$ Daar blijft het echter niet bij. Ook over de roman Bright Lights, Big City (1984) van McInerey laat Römer zich uit: "Zo lijkt het eerste hoofdstuk uit de Amerikaanse roman model te hebben gestaan voor het hoofdstuk 'Mondriaan-vlinders' [p. 19-26] in Gimmick!" 46

Römer noemt als Nederlandse invloed De avonden (1947) van Gerard Reve (1923-2006), maar daar wil ik Turks Fruit (1969) van Jan Wolkers (1925-2007) aan toevoegen, getuige het laatste hoofdstuk in Gimmick! dat als titel heeft 'Een hoofd met een deurtje'. Dit verwijst naar de verwijderde tumor in Olga's hoofd. Net zoals kunstenaar Raam een heftige liefde voor Sam opvat heeft de hoofdpersoon van Turks Fruit die voor Olga en in beide gevallen maken de dames een einde aan hun verhouding omdat de mannen een te grote bezetenheid en seksuele bezitsdrang hebben. De intertekstualiteit is niet alleen kenmerkend voor het oeuvre van Zwagerman, met name voor Gimmick!, maar Römer voegt daaraan toe: "Deze intertekstuele denk- en werkwijze is een fundamenteel aspect van het postmodernisme in de literatuur. Teksten, uitingen van zowel 'serieuze' als 'populaire' kunst worden samengebracht, waardoor de grens tussen cultuur en massacultuur vervaagt. Postmodernisme: de schrijver een kopiist, de wereld een immense bibliotheek waaruit wordt geleend". 47

Dat citeren, samplen, plagiëren dan wel intertekstualiteit moeilijk van elkaar te onderscheiden zijn, concludeert ook Marcel Janssens:

Hun [de groep rond het literaire tijdschrift Zoetermeer, waartoe ook Zwagerman gerekend wordt] manieren van overschrijven, hun samplingprocedures combineren een esthetiek van de identiteit (of van de imitatio) met een esthetiek van de oppositie (of van de creatio, in een vorig discours: van originaliteit): identiteit op het niveau van het nagebootste of gekopieerde materiaal, oppositie op het niveau van de tekst-verwerking van het toegeëigende materiaal, en daar kan dan een spoor van originaliteit in te bespeuren vallen. ${ }^{48}$

Dit procedé hanteren de personages in de roman eveneens. Zo is de protagonist in Gimmick! beeldende kunstenaar. De beeldende kunst van de jaren tachtig speelt dan ook een belangrijke rol. Zoals aangetoond han- 
teert Zwagerman vaak het procedé van het citaat, maar hij doet dat niet alleen met literatuur, maar ook met de beeldcultuur.

Römer merkt op hoe de contemporaine beeldcultuur de personages beïnvloedt, zelfs in die mate dat hij beweert: "Hun gedachten en gevoelens worden omgezet in beelden, of vergeleken met scènes uit films, reclamespots of videoclips". ${ }^{49}$ Een voorbeeld hiervan is als Raam met Groen en Eckhardt in Deel 2 op het strand van Tenerife is:

Het water is helder. De lucht is blauw, net als het zeewater. De toppen van rotsen trillen in de zon. [...] Maar als ik het water uitloop, loop ik niet het water uit maar actéer ik dat ik het water uitloop. Ik bedoel, alleen de wereld van Peter Stuyvesant is uiteindelijk de best denkbare wereld'. ${ }^{50}$

Dit is het decor dat bekend is geworden door de reclames van het sigarettenmerk en waarin Raam zich niet geheel als zichzelf beweegt, maar eveneens een rol zegt te spelen. Het is een door de reclame geïdealiseerde wereld. Hoezeer reclamebeelden hem beïnvloeden, blijkt ook wanneer hij de commissie die over de subsidie moet beslissen in zijn atelier dia's met zijn eigen werk laat zien: "De dia's van mijn meest postmoderne schilderijen met titels als 'Pall Mall', 'Artists unlimited' en 'The choice for a new generation"." 51 Dit geldt eveneens voor de "tientallen op elkaar gestapelde pakken Dash-waspoeder". ${ }^{52}$ De verwijzingen naar postmoderne beeldende kunst zijn in Gimmick! sterk aanwezig, zodat gezegd kan worden dat Zwagerman schrijft in een met citaten gelardeerde roman over een beeldende kunstenaar die in de ik-persoon zijn verhaal vertelt - hij en zijn collega's passen eveneens het citeren in hun werk toe. Daarin komen ze overeen met de kunstenaars die in die periode in Amsterdam actief waren.

\section{$4 \quad$ De kunst buiten Gimmick!}

Het postmoderne citeren is niet alleen intertekstueel, maar een complete kunststroming wordt de roman ingetrokken om de personages te maken tot wie ze zijn. In de paragraaf die Zima in Der europäische Künstlerroman aan Gimmick! wijdt, laat hij de kunst zelf die in de roman zo'n belangrijke rol speelt buiten beschouwing. Zonder een bepaald personage één op één aan een bepaalde werkelijk bestaande kunstenaar te koppelen, kan het wel een richting aanwijzen. Zoals gezegd, zag Rob Scholte bepaalde overeenkomsten tussen zichzelf en een personage. Zonder daarmee in te stemmen kan wel gezegd worden dat in de jaren tachtig een groep 
kunstenaars, waarvan ook Zwagerman deel uitmaakte, actief was. In het $N R C$ schrijft Paul Steenhuis op 31 maart 1995:

Scholte maakte begin jaren tachtig deel uit van een vriendenkring van jonge kunstenaars, die samen de wereld wilden veroveren. Ze verzamelden zich rond galerie The Living Room, in 1981 opgericht in de gezamenlijke Amsterdamse huiskamer van kunstenaar Peer Veneman en kunstgeschiedenisstudent Bart van de Ven. Kunstenaars als Martin van Vreden, Aldert Mantje en Harald Vlugt behoorden ook tot de galerie. Ze kwamen in het café Het Paleis andere jongere kunstenaars tegen, net als zij deels afkomstig uit het Amsterdamse kraakcircuit. Schrijver Joost Zwagerman, die ook bij de groep hoorde, heeft erover geschreven in zijn roman Gimmick! ${ }^{53}$

Maar het gaat vooral om de kunst waarvan in de roman sprake is en die gerelateerd is aan de groep rond Rob Scholte. Naar aanleiding van de opening van een overzichtstentoonstelling van zijn werk in museum Boijmans Van Beuningen in Rotterdam met de titel Rob Scholte, how to star gaf Scholte een toelichting op zijn werk:

Dit is de tijd van volstrekte kunstmatigheid, van genetische manipulatie, van kunstmatige intelligentie. Een verraderlijke tijd, want alles is dubbel. We zitten in een beslissende evolutiefase, die knetterhard is. In mijn werk ben ik bezig met unica en duplicaten. Ik monteer en ik kloon beelden. Noem me de Dr. Mengele van de kunst. ${ }^{54}$

Behalve dat de titel van zijn tentoonstelling duidt op de marktstrategieën en het streven naar roem, wordt ook het begrip originaliteit anders bezien dan moderne kunstenaars dat eerder deden.

Die veranderde poëticale opvatting omtrent originaliteit ziet ook Rudi Fuchs. ${ }^{55}$ De voormalig museumdirecteur omschrijft de groep kunstenaars die in de jaren tachtig van de twintigste eeuw actief werd als een groep die zich niet meer verplicht voelt zich aan de idee van de moderne kunst te houden - "de verplichting om vorm, kleuren, een compositie naar hun zuiverste formulering te brengen". 56 De groep bestaat volgens hem uit Rob Birza (1962), Rob Scholte (1958), Emo Verkerk (1955), Bart Domburg (1957) en Peter Klashorst (1957). Ze zijn met televisie opgegroeid en zijn doordrongen van het snellere levensritme van de Amerikaanse cultuur. Ze zijn eigengereid en brutaal: 
Met een laconieke en ironische onderwerpkeuze en een even laconieke manier van uitvoering leken hun schilderijen, niet zelden spotziek, op een persiflage van de heilige moderne kunst. Voor hen leed het geen twijfel dat de hoopvolle verwachtingen waarmee de twintigste eeuw begonnen was (en waar zij lang in bleven geloven) gestrand waren. Hun wereld was een andere; sinds rock-'n-roll was de muziek veranderd; de nieuwe media pompten onophoudelijk duizenden beelden door hun hoofd; het nieuwe icoon was Andy Warhol. ${ }^{57}$

Deze typering komt overeen met wat Jeroen Boomgaard en Sebastián López schrijven in de inleiding bij de bundel Van het postmodernisme (1985) die in de jaren tachtig een belangrijke van oorsprong Nederlandstalige introductie vormt tot het postmodernisme, nog voor de vertaling van werk van de Franse filosoof Jean-François Lyotard (1924-1998). De deelnemende auteurs, die elk een andere discipline vertegenwoordigen, vatten het postmodernisme niet op als een beweging of als iets waar men voor of tegen kan zijn, maar als een postmoderne conditie: "Wij leven in een postmoderne konditie, wij leiden een postmodern leven. ${ }^{58}$ Niet wij kiezen het postmodernisme maar het heeft ons gekozen". 59 Als algemene typering geven zij de willekeurige vorm, de afwezigheid van kunst als uitdrukking in vorm en stijl van een utopie dit in tegenstelling tot het modernisme. Het gevolg zijn de vele stijlen die in het postmodernisme terug te vinden zijn. ${ }^{60}$

In Aesthetic Investigations spreekt Rob van Gerwen over 'appropriation', toe-eigening, omdat hij eerst de algemene vraag stelt wanneer bij een publicatie sprake is van reproductie met het oog op de schending van het 'image right', het beeldrecht of 'the secondary use of depictions'. 61 Daarna specificeert hij de vraag: "Should we distinguish appropriation of famous works which still stand on their own, and are, so to speak, advertised by appropriation; and appropriation of works perhaps forgotten, that are reanimated by the appropriation?". ${ }^{62}$ De vraag is niet zo moeilijk te beantwoorden wanneer het gaat om dezelfde afbeelding in twee verschillende media, zoals het geval is met de foto die Katrijn Van Giel (1983) maakte van de Belgische politicus Jean-Marie De Decker die zojuist de verkiezingen verloren had. Van die foto makte Luc Tuymans (1958) een schilderij. Ondanks dat hetzelfde tafereel is weergegeven gaat het om twee verschillende kunstwerken. Maar al zouden ze geheel identiek zijn dan nog hebben ze verschillende betekenissen, ${ }^{63}$ omdat de één een journalistieke foto over een politieke gebeurtenis is en de andere een olieverfschilderij dat zeker geen journalistiek doel dient. Van Giel ging 
naar de rechtbank en kreeg gelijk, omdat de rechter geen verschil zag tussen de foto van de foto en de foto van het schilderij die hij het publiek toonde en waarbij hij de retorische vraag stelde of iemand het verschil kon zien.

Rob Scholte speelt met dit soort kwesties. Hij vat zijn werken op als een soort recepten aan de hand waarvan anderen het werk mogen maken:

So his interest is not in realising his intentions through the manipulation of materials by his own hands, but there is still a sense of achievement in the nature of his recipes, as well as a conceptual consistency amongst them. Also, once these works are finished, Scholte does not claim that either he or his co-workers are the sole determinants of the works' meanings. ${ }^{64}$

Scholte kan zijn werk zien als recepten, omdat de hedendaagse mens blootgesteld is aan een 'bombardement' van beelden via televisie, internet en reclame. Bij al die beelden waaraan wij ongevraagd blootgesteld worden, kan de vraag gesteld worden hoe dat zich verhoudt tot het 'image right'. Van Gerwen voert aan dat het beeldrecht maar de helft van de kwestie is: "the owner of the image manoeuvers other people by demanding that they watch the image only in the manner desired by the maker or their legal representative". ${ }^{65}$ De andere helft betreft de kijkers, want zij zijn degenen die deze beelden waarnemen. Scholte tracht in dat immense beeldaanbod toch beelden te presenteren waarvan we niet bewust zijn dat we ze zien. ${ }^{66}$ Dat doet hij door al bestaande beelden als het ware te reanimeren. Zo gebruikt hij vaak beroemde logo's van merken in zijn werk, zo schilderde hij het teken van copyright - (C) - dat zo een kunstwerk werd van een symbool dat dat kunstwerk zou moeten beschermen (zie afbeelding 1, Self Portrait). Het kunstwerk laat ook zien dat het copyrightsymbool eveneens een kunstwerk is, terwijl de meesten bij het zien van het symbool aan een juridische betekenis denken. Wanneer dit procedé gebruikt wordt bij uit de mode of gratie geraakte beelden, kan gezegd worden dat Scholte ze reanimeert, met als gevolg dat kunst levend blijft. 


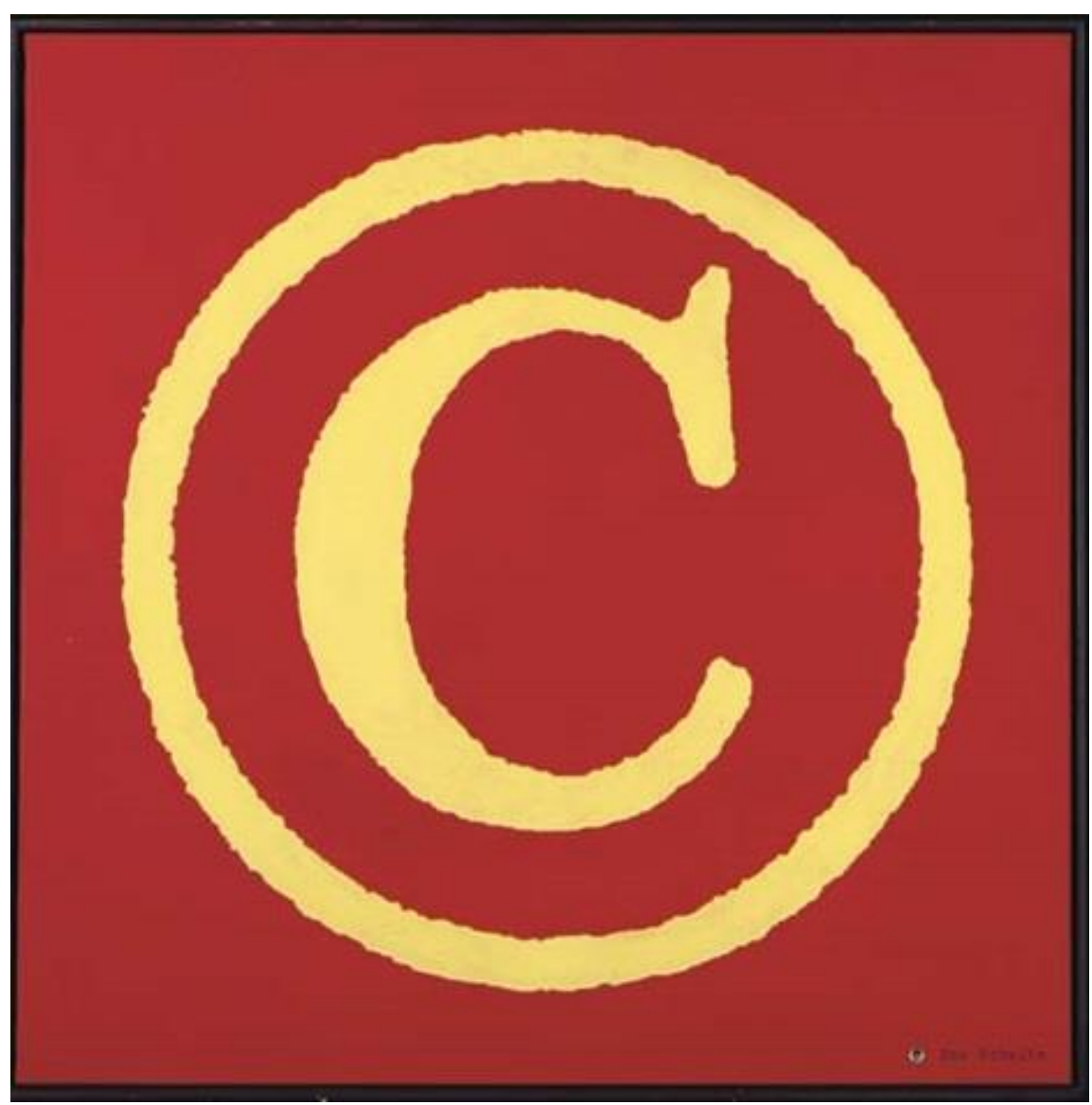

Afbeelding 1: Rob Scholte, Self Portrait (1988)

Paul Depondt werpt de vraag op of de schilder dan ironische plaatjes van een plaatje maakt. ${ }^{67}$ De verandering van context, de herbewerking of de toe-eigening vormen in elk geval ook een kritiek op de beeldvorming van de 'werkelijkheid' zoals die door de massamedia is vormgegeven. Rob van Gerwen verwoordt het als volgt:

Rob Scholte does not make pictures of things, people or events. He makes images, by reanimating existing ones-though sometimes he makes new ones, as well. A good artist tells in his work how it is that we should appreciate it. Rob Scholte is a good artist. He is not committed to a style. His style is a way of seeing. He sees images and, for us, brings them back to life. ${ }^{68}$ 
De kunstenaar blijft uiteindelijk een ziener, al is hij niet meer de ziener die hierboven met betrekking tot het modernisme genoemd wordt. Hij ziet, maar hij ziet anders en hij ziet andere beelden.

\section{Slot}

Walter van Raamsdonk is beeldend kunstenaar maar is op geen enkele manier met zijn werk bezig, veroorzaakt door zijn liefdesverdriet. In de periode die zich afspeelt voordat het boek begint, is hij een veelbelovend postmodern kunstenaar. Zijn postmoderne climax bereikt hij als hij met werk van een ander, van Alex Menkveld, een subsidie krijgt toegewezen. Hierin zit het paradoxale karakter van Gimmick!. Als schrijver van een postmoderne kunstenaarsroman geeft hij commentaar op de postmoderne beeldende kunst en zegt in wezen dat van kunst niets anders resteert dan een paradox. Dit wordt versterkt door het begrip originaliteit te herdefiniëren en vooral op te rekken. Stoop, die met een film aan de tentoonstelling 'The Amsterdam Dream' deelneemt, zegt dat het typisch voor de jaren tachtig en negentig is dat alles lijkt te mogen: "Werd er maar weer eens wat verboden of gecensureerd". ${ }^{69}$ Zima constateert hoe waarden in tegenstellingen als waar-onwaar, origineel-namaak en goed-slecht aan het wankelen geraakt zijn. ${ }^{70}$

Seret presenteert vier voyages die kenmerkend zijn voor de kunstenaarsroman. Opvallend is dat Gimmick! aan geen enkele voldoet. Raam legt door zijn blokkade geen enkele reis af, in het beste geval is het einde van de roman te duiden als Raams afscheid van de kunst - omdat het meisje met de zonnebril hem vraagt wat hij nu eigenlijk wil en hij enkel de vraag weet te herhalen - of hij wijdt zich weer aan kunst en dat hoeft niet per se de postmoderne kunst te zijn, omdat discotheek Gimmick niet meer het centrum van de postmoderne kunstscène is, maar onder provincialen populair geraakt is. Hoewel Gimmick! niet voldoet aan Serets vier voyages, ziet Zima Zwagermans tweede roman terecht als een typisch postmoderne kunstenaarsroman. Dit heeft te maken met de rol die kunst daarin speelt door het marktdenken en het opnemen van het aandeel dat de media daarin heeft in de roman. Er is geen reis als je citeert of plagieert. Hoe zit dat in de postmoderne kunstenaarsroman? Het is dan ook maar de vraag of Walter van Raamsdonk zijn homeland zal bereiken.

De personages in de roman passen hetzelfde productieprocedé toe als de groep jonge kunstenaars in de jaren tachtig in Amsterdam. De roman is 
met behulp van hetzelfde procedé tot stand gekomen en draagt dezelfde poëticale opvattingen uit.

Noten

1 Gimmick! verscheen in 1989, maar hier is uitgegaan van de herdruk uit 2006 die verscheen in de 15-delige reeks 'Kopstukken', een speciale uitgave van Wegener Dagbladen NV, nu onderdeel van De Persgroep.

2 Zima, 'Kunst als gimmick: Joost Zwagerman'.

Kraaijeveld, 'Joost Zwagerman: Gimmick!', 599.

4 Seret, Voyage Into Creativity. The Modern Künstlerroman, 9.

Ibidem.

6 Seret, Voyage Into Creativity, 10.

7 Seret, Voyage Into Creativity, 12.

8 Ibidem.

9 Seret, Voyage Into Creativity, 1.

10 Zima, Der europäische Künstlerroman. Von der romantischen Utopie zur postmodernen Parodie, 368.

11 Idem, 273.

12 Ibidem.

13 Zima, Der europäische Künstlerroman, 274.

14 Ibidem.

15 Zima, Der europäische Künstlerroman, 277.

16 Idem, 371.

17 Thompson, The Concise Oxford Dictionary of Current English, 571.

18 Zwagerman, Gimmick!, 48.

19 Idem, 29.

20 Zwagerman, Gimmick!, 221.

21 Zwagerman, Gimmick!, 14.

22 Idem, 53.

23 Zwagerman, Gimmick!, 143.

24 Idem, 200.

25 Zima, Der europäische Künstlerroman. Von der romantischen Utopie zur postmodernen Parodie, 375.

26 Zwagerman, Gimmick!, 50.

27 Ibidem.

28 Zwagerman, Gimmick!, 205.

29 Zwagerman, Gimmick!, 143.

30 Zwagerman, Gimmick!, 230.

31 Zwagerman, Gimmick!, 231-232.

32 Zwagerman, Gimmick!, 237.

33 Zwagerman, Gimmick!, 69-70.

34 Zwagerman, Gimmick!, 191. 
35 Zwagerman, Gimmick!, 243.

Zwagerman, Gimmick!, 202.

Zwagerman, Gimmick!, 204.

Janssens, 'Postmodern Dutch literature: Renewal or tradition', 193.

Ibidem.

40 Seijdel, 'Made in the USA.'

41 Römer, 'Gimmick! Proust, Brat Pack en The Shangri-Las', 38.

${ }^{42}$ Zwagerman, Gimmick!, 117.

43 Römer, 'Gimmick! Proust, Brat Pack en The Shangri-Las', 38.

44 Idem, 39.

45 Ibidem.

46 Römer, 'Gimmick! Proust, Brat Pack en The Shangri-Las', 40.

47 Idem, 38.

48 Janssens, 'Plagiaat, 'plagiaat', of (plagiaat)?', 185.

49 Römer, 'Gimmick! Proust, Brat Pack en The Shangri-Las', 38.

50 Zwagerman, Gimmick!, 127.

51 Idem, 200.

52 Zwagerman, Gimmick!, 237.

53 Steenhuis, 'De weerstand van de kunstenaar; Schilder Rob Scholte na de aanslag op zijn leven'.

54 De Jong, Wat een kunst! Twaalf toppers uit de moderne kunst, 49.

55 Rudi Fuchs kan herkend worden in het personage dat tijdens de opening van 'The Amsterdam Dream' beschreven wordt als: 'De museumdirecteur, een contactgestoorde calvinist met een kogelronde kop en een ziekenfondsbrilletje, neuzelt iets vaags in de microfoon en laat zich intimideren door de televisiecamera's en het geflits van de persfotografen' (Zwagerman, Gimmick!, 231). Fuchs was van 1987 tot 1993 directeur van het Haags Gemeentemuseum en van 1993 tot 2003 van het Stedelijk Museum in Amsterdam.

56 Fuchs, Schilderen in Nederland, 245.

57 Idem, 247.

58 Het invloedrijke werk van Jean-François Lyotard heeft als titel La condition postmoderne - rapport sur le savoir (1979).

59 Boomgaard \& López, 'Inleiding', 9.

60 Ibidem.

${ }^{61}$ Gerwen, 'Copyright and Watch Duty. Rob Scholte's Work. Part I', 308-309.

62 Idem, 310.

63 Ibidem.

${ }^{64}$ Gerwen, 'Copyright and Watch Duty. Rob Scholte's Work. Part I', 313.

65 Idem, 316.

${ }^{66}$ Gerwen, 'Reanimation and Copywright. Rob Scholte's Work. Part II', 76.

67 Depondt, 'De ondraaglijke lichtheid van Rob Scholte: plagiaat?', 278.

68 Gerwen, 'Reanimation and Copywright. Rob Scholte's Work. Part II', 85.

69 Zwagerman, Gimmick!, 238. 
70 Zima, Der europäische Künstlerroman. Von der romantischen Utopie zur postmodernen Parodie, 380-381.

\section{Bibliografie}

Boomgaard, Jeroen \& López, Sebastián. 1985. 'Inleiding.' Boomgaard, Jeroen \& López, Sebastián (red.) Van het postmodernisme. Amsterdam: SUA.

Depondt, Paul. 1989. 'De ondraaglijke lichtheid van Rob Scholte: plagiaat?' Ons Erfdeel. Jaargang 32, 278-279.

Fuchs, Rudi. 2004. Schilderen in Nederland. De geschiedenis van 1000 jaar kunst. Amsterdam: Bert Bakker.

Gerwen. Rob van. 2016. 'Copyright and Watch Duty. Rob Scholte's Work. Part I.' Aesthetic Investigations. Vol. 1/No. 2 308-318.

Gerwen. Rob van. 2017. 'Reanimation and Copywright. Rob Scholte's Work. Part II.' Aesthetic Investigations. Vol.2/No. 1, 76-87.

Janssens, Marcel. 1997 'Plagiaat, 'plagiaat', of (plagiaat)?' Verslagen en mededelingen van de Koninklijke Academie voor Nederlandse taal-en letterkunde. Jaargang 1997. Gent: Koninklijke Vlaamse Academie voor Taal-en Letterkunde, 177-193.

Janssens, Marcel. 2016, 'Postmodern Dutch Literature: Renewal or Tradition.' Narratives of Low Countries History and Culture. London: UCL Press, 192-198. https://doi.org/10.2307/j.ctt1hd18bd.24

Jong, Klaas de. 2005. Wat een kunst! Twaalf toppers uit de moderne kunst. Haarlem: J.H. Gottmer/H.J.W. Becht.

Kraaijeveld, Ruud A.J. 1989. 'Joost Zwagerman: Gimmick!'Ons Erfdeel Jaargang 32, 598-599.

Römer, Paul. 1994-1995. 'Gimmick! Proust, Brat Pack en The ShangriLas.' Bzzlletin. Jaargang 24, 37-43.

Seijdel, Jorinde. 1989. 'Made in the USA.' Metropolis $M$, jrg. 10, nr. 1, $12-16$.

Seret, Roberta. 1992. Voyage Into Creativity. The Modern Künstlerroman. New York: Peter Lang.

Steenhuis, Paul. 1995. 'De weerstand van de kunstenaar; Schilder Rob Scholte na de aanslag op zijn leven.' In: NRC Handelsblad, 31 maart 1995. 
Thompson, Della, 1995. The Concise Oxford Dictionary of Current English. Oxford: Oxford University Press.

Zima, Peter V. 2007. 'Kunst als gimmick': Joost Zwagerman.' Brief aan Beatrix en 22 andere opstellen over de roman en de romanbeschouwing. Antwerpen: https://www.dwbarchief.be/uitgave/2007/5/brief-aan-beatrix-en-22andere-opstellen-over-de-roman-en-de-romanbeschouwing/peterv.html

Zima, Peter V. 2008. Der europäische Künstlerroman. Von der romantischen Utopie zur postmodernen Parodie. Tübingen-Basel: A. Francke. Zwagerman, Joost. 2006. Gimmick! . Apeldoorn: Wegener Dagbladen. 